\title{
Artritis séptica esternoclavicular
}

Sternoclavicular septic arthritis

\author{
BERROCAL Alfredo ${ }^{1}$, FERRANDIZ Manuel ${ }^{1}$, ECHEVARRIA Juan ${ }^{2}$, GOTUZZO \\ Eduardo $^{2}$, CALVO Armando ${ }^{1}$, SILICANI Armando ${ }^{1}$. \\ ${ }^{1}$ Departamento de Medicina. Unidad de Inmunología y Reumatología. Hospital Nacional \\ Cayetano Heredia. Universidad Peruana Cayetano Heredia. \\ ${ }^{2}$ Instituto de Medicina Tropical “Alexander Von Humbold”. Universidad Peruana Cayetano \\ Heredia.
}

\section{SUMMARY}

We report nine patients with sternoclavicular septic arthritis (SSA), two of whom were intravenous drug abusers, none of them were heroin users. The average age was 34.5 years old. SSA was more frecuent in males than in females. We isolated the causal microrganism in six patients, the microorganism most commonly found was $S$. Aureus. All the patients treated (8) had a good response. (Rev Med Hered 1993; 4: 125128)

KEY WORDS: Septic, esternoclavicular joint arthritis, heroin user, arthritis

\section{RESUMEN}

Reportamos nueve pacientes con artritis séptica esternoclavicular (ASEC), dos de los cuales fueron adictos a drogas endovenosas, pero en ningún caso a heroína. La edad promedio fue de 34.5 años. El sexo más frecuente fue el masculino. En seis pacientes se aisló el microorganismo causal, siendo el más frecuentemente aislado el Stafilococo aureus. Ocho pacientes fueron tratados y tuvieron excelente respuesta. (Rev Med Hered 1993; 4:125-128)

PALABRAS CLAVE: Séptica, artritis esternoclavicular, adicción a herína, artritis.

\section{INTRODUCCIÓN}

La artritis séptica (AS) es una infección severa que compromete usualmente grandes articulaciones (1), pero que puede afectar regiones inusuales como la articulación esternoclavicular (EC) $(2,3)$.

Esta localización que se ha descrito mayormente en sujetos adictos a drogas endovenosas $(2,4)$; nosotros la reportamos en 9 pacientes con AS, siete de los cuales no presentaban historia de drogadicción.

MATERIAL Y MÉTODOS 
Se realizó un estudio retrospectivo mediante la revisión de las historias clínicas de los pacientes mayores de 14 años diagnosticados de artritis séptica (AS) en el Hospital Nacional Cayetano Heredia entre abril de 1969 y agosto de 1992.

Se seleccionaron los pacientes con diagnóstico definido, probable o posible de artritis séptica esternoclavicular (ASEC). Se consideró diagnóstico definido de ASEC cuando existía cuadro clínico de dolor y/o aumento de volumen EC y aislamiento del germen del líquido sinovial o por hemocultivo. Se catalogó como diagnóstico probable todo caso con cuadro clínico compatible en quien se aisló el germen de otro foco diferente al líquido sinovial o sangre. Se estableció diagnóstico posible de ASEC en aquel paciente con cuadro clínico compatible y evolución favorable al tratamiento antibiótico, pero en quien no se logró recuperar ningún germen (3).

Se excluyeron los pacientes con artritis EC por brucella, que son motivo de otra comunicación (5).

\section{RESULTADOS}

Entre abril de 1969 y agosto de 1992 se diagnosticaron 106 pacientes con AS en el Hospital Nacional Cayetano Heredia; 9 de ellos $(8.5 \%)$ tuvieron compromiso EC, siendo unilateral en todos los casos.

Seis fueron varones, la edad promedio fue 34.5 años con un rango de 15 a 61 años, el tiempo de enfermedad varió entre 2 a 45 días, sólo 2 pacientes presentaron antecedentes de drogadicción endovenosa (Cuadro $\left.\mathrm{N}^{\circ} 1\right)$.

Se diagnosticaron 6 casos de artritis definida, aislándose Stafilococo aureus en 3 de ellos (uno la desarrolló en el curso de una sepsis y otro era drogadicto), Salmonella Typhi en dos casos y Streptococo pneumoniae en uno (tuvo además neumonía y meningoencefalitis); en 2 casos se diagnosticó artritis gonocócica probable y un paciente tuvo artritis séptica posible; este último era drogadicto ( $\left.\underline{\mathrm{Cuadro}^{\circ} 2}\right)$.

Se tomaron radiografías EC en 4 pacientes, estas fueron normales en dos casos, mientras que en los dos restantes mostraron signos de osteomielitis del tercio proximal de la clavícula. En un paciente se realizó scan óseo que mostró aumento de captación en la articulación EC afectada.

La artritis producidas por Stafilococo aureus fueron tratadas con oxacilina 4-6gr/d EV por 2-3 semanas y luego dicloxacilina VO por 2-4 semanas más; un paciente con Salmonella Typhi recibió ciprofloxacina $1 \mathrm{gr} / \mathrm{d}$ VO por 8 semanas; el otro con Salmonella Typhi no recibió tratamiento porque pidió su retiro voluntario. El paciente con artritis neumocócica recibió Penicilina (PNC) g sódica 24 millones U/d EV por 2 semanas.

Las artritis gonocócicas probables recibieron PNC G sódica 12 millones U/d EV por 4-6 días y luego ampicilina $2 \mathrm{gr} / \mathrm{d}$ VO hasta completar 10 días de tratamiento; el paciente con ASEC posible se trató con cefalosporina por 4 semanas ( $\underline{\text { Cuadro } \mathrm{N}^{\circ} 3}$ ) 


\section{DISCUSIÓN}

La artritis séptica es una infección de la cavidad articular que generalmente se adquiere por siembra hematógena debido a que la sinovia es un tejido muy vascularizado que no presenta membrana basal limitante lo que permite un fácil acceso de los gérmenes durante una bacteriemia (1).

La articulación EC es susceptible de invasión bacteriana pues comprende dos cavidades tapizadas por tejido sinovial, separadas por un disco fibrocartilaginoso. Es probable además que los cambios degenerativos que sufre a partir de la tercera década de la vida favorezcan infecciones a este nivel (3).

Por la prevalencia de artritis séptica EC en drogadictos se ha postulado que la inyección intravenosa de material contaminado llevaría a una tromboflebitis subclavia con artritis piógena EC por contigüidad $(2,4)$. Otros autores propugnan que existe cierto tropismo o predilección por articulaciones fibrocartilaginosas en casos de artritis séptica en estos pacientes (6).

El compromiso bacteriano EC ocurre en $9 \%$ de los casos de artritis séptica $(3,7)$, nosotros hallamos un porcentaje similar $8.5 \%$. A diferencia de las demás articulaciones, el inicio de síntomas es generalmente insidioso, con fiebre leve a moderada y dolor EC algunas veces hasta de un mes antes del diagnóstico (8). Signos como eritema, calor local y tumefacción articular son prominentes y en ocasiones el dolor puede limitar el movimiento del hombro homolateral $(3,8)$

Entre las bacterias que pueden causar infección EC se describen el Stafilococo aureus, Streptococo sp., Streptococo pneumoniae, Pseudomona aeruginosa, Escherichia coli, Hemophilus influenziae, Salmonella sp., Brucilla melitensis, y especies de bacteroides y neiseria $(2,5,9)$.

En la mayoría de los casos de artritis séptica EC el germen más frecuente es Stafilococo aureus (10); en casos de drogadicción endovenosa los gérmenes recuperados han sido generalmente bacilos gramnegativos, fundamentalmente Pseudomona aeruginosa; estos pacientes parecen tener predisposición a la infección EC por pseudomona $(2,4,1)$. Son de localización EC el 25\% de todos los casos reportados de artritis por pseudomona y el 50\% de las artritis por pseudomona ocurren en adictos a drogas endovenosas (3).

De nuestros 9 pacientes, tres tuvieron artritis EC por Stafilococo aureus, uno la desarrolló en el curso de sepsis y otro fue drogadicto. Entre 1973 y 1983 se trataron en nuestro hospital 58 casos de sepsis por Stafilococo aureus, 6 de ellos (10.3\%) presentaron artritis, aparentemente ninguno de localización EC; la mayoría fueron jóvenes y el 95\% tuvo como puerta de entrada una infección dérmica (12), nuestro paciente con artritis EC desarrollada en el curso de sepsis resalta por la infrecuencia de su localización.

El compromiso osteoarticular en salmonelosis generalmente es por especies no Typhi, observándose 3 cuadros distintos: artritis reactiva, artritis séptica y osteomielitis $(12,14)$. 
Diferentes estudios han mostrado una fuerte asociación entre HLA B27 y artritis reactiva post-salmonelosis, señalando algunos autores una positividad hasta de 100\% (14). Artritis séptica y osteomielitis tienen como factores pre disponente el falciformismo, neoplasias, alcoholismo, terapia inmunosupresora y las enfermedades del tejido conectivo, principalmente Lupus Eritematoso Sistémico $(13,15,19)$.

La fiebre tifoidea es una enfermedad de alta prevalencia en países subdesarrollados (20), describiéndose compromiso osteoarticular infrecuentemente. Esto también ocurrió en nuestro hospital, así entre 1976 y 1983 se atendieron 645 pacientes con fiebre tifoidea, de los cuales 25 (3.9\%) tuvieron artritis y osteomielitis (21).

El compromiso EC por salmonella fue descrito por primera vez en 1896 aislándose Salmonella paratyphi (13). Recientemente Ayensa reportó un paciente alcohólico en quien se recuperó S. no Typhi grupo D de la articulación EC (16). La mayoría de especies de salmonella aisladas en artritis séptica son no Typhi; así nuestros pacientes destacan por el aislamiento de Salmonella Typhi de la articulación EC y por la ausencia de enfermedad subyacente.

El neumococo es causa infrecuente de artritis séptica $(1,8)$ habitualmente se presenta como resultado de bacteriemia a partir de un foco neumocócico (neumonía, meningitis). Un alto porcentaje de pacientes tienen condiciones predisponentes, como alcoholismo y enfermedad articular previa (22). La mayoría de casos comprometen rodillas, describiéndose ocasionalmente afección EC (18). Nuestro paciente destaca por su presentación infrecuente.

La artritis gonocócica se presenta clásicamente como una poliartritis migratoria que subsecuentemente se localiza en una o más articulaciones; las articulaciones mayormente afectadas son las rodillas, aunque cualquier articulación puede comprometerse (24). El compromiso EC frecuente en la era preantibiótoca, no ha sido visto en series más recientes (24) por lo que nuestros dos pacientes llaman la atención.

De los 9 pacientes con artritis esternoclavicular solo 2 eran drogadictos. Aunque se menciona que bacilos gramnegativos (mayormente pseudomona) son los gérmenes más frecuentemente aislados en casos de drogadicción endovenosa, esto podría variar según el área geográfica, así por ejemplo en España se reporta que el germen más frecuente en adictos a drogas intravenosas es estafilococo, contrario a lo que sucede con series anglosajonas en las cuales la pseudomona es el más descrito (25).

Con este trabajo queremos resaltar la posibilidad de infección EC en nuestro medio, en pacientes sin antecedentes de drogadicción.

\section{Correspondencia:}

Dr. Alfredo Berrocal. Unidad de Inmunología y Reumatología, Hospital Nacional Cayetano Heredia. Av. Honorio Delgado s/n. San Martín de Porres. Lima-Perú.

\section{REFERENCIAS BIBLIOGRAFICAS}


1.Goldenberg D, Reed R. Bacterial artritis. N Engl J Med 1985; 312:764-771.

2.Bayer A, Chow A, Lowe J, Guze L. Sternoclavicular pyoarthrosis due to gram negative bacilli. Arch Intern Med 1977; 137:1036.

3.Yood R, Goldenberg D. Sternoclavicular Joint Arthritis. Arthr Rheum 1980; 23: 232-239.

4.Goldin R, Chow A, Edward J et al. Sternoclavicular septic arthritis in heroin users. N Engl J Med 1973; 289:616-618.

5.Berrocal A, Gotuzzo E, Castañeda O, Carrillo C, Calvo A, Alarcón G. Artritis sternoclavicular por Brucella melitensis. J Rheumatol 1993; 20:1184-1186.

6.López F, Minard H, Carreño L, Cosin I, Ballesteros R, Monteagudo I. Primary septic arthritis in heroin users. J Rheumatol 1987; 14: 991-994.

7.Goldenberg D, Cohen A. Acute infectious arthritis. Am J Med 1976; 60: 369-377.

8.Goldenberg D. The evaluation of patients with nongonococcal bacterial arthritis. In: Espinoza L, Goldenberg D, Arnett F, Alarcón G(eds). Infections in the Rheumatic Diseases. G \& S Inc. Orlando, 1988; pp 9-17.

9.Berrocal A, Gotuzzo E, Calvo A. Artritis Esternoclavicular. Bol Asoc Per Reumatol $1991 ; 10: 82-84$.

10. Gillis S, Friedman B, Caracs Y, Blankstein A, Yellin A, Friedman G. Septic arthritis of the sternoclavicular joint in the healthy adults. J Intern Med 1990; 228:275-278.

11.Gifford D, Patzakis M, Ivler D, Swezwy R. Septic Arthritis due to pseudomona in heroin addicts. J Bone Joint Surg (Am) 1975; 67:631-635.

12.Mera M, Gotuzzo E. Septicemia a S. Aureus (abstracto). Libro de Resúmenes II Congreso Nacional de Medicina Interna, Lima 1984.

13.Cohen J. Bartlett J, Corey R. Extraintestinal Manifestations of Salmonella Infections. Medicine 1987; 66:349-388.

14.Hanner T, Leinsalo-Repo M. Clinical picture of reactive Salmonella arthritis. J Rheumatol 1988; 15:1668-1671.

15.Campos P, Berrocal A, Gotuzzo E, Calvo A. Compromiso osteoarticular por Salmonella. Rev Med Hered 1990; 1(2):47-49.

16.Ayensa C, Ruiz F Agud J, Cid J. Artritis por Salmonella no Typhi. Rev Esp Reumatol 1988; 15:145-146.

17.Ortiz-Neu C, Mari J, Cherubin C, Neu H. Bone and Joint infections due to Salmonella. J Infect Dis 1978; 138:820-828.

18.Van de Laar M, Meenhorst P, Van Svesberzen R, Olstoorn P. Polyarticular Salmonella bacterial arthritis in a patients with Systemic Lupus Erythematosus. J Rheumatol 1989; 16: 231-234.

19.Medina F, Fraga A, Lavalle C. Salmonella septic arthritis in SLE: The importante of chronic carrier state. J Rheumatol 1989; 16: 203-208.

20.Gotuzzo E. Epidemiología de Fiebre Tifoidea. Diagnóstico 1981; 8: 76-81.

21.Gotuzzo E, Calvo A, Bocanegra T, Guerra J, Echevarría J, Sánchez J. Fiebre Tifoidea y artritis (abstracto). Libro de Resúmenes VII Congreso Bolivariano de Reumatología, Lima 1984.

22.Kauffman C, Watanukakom Ch, Phair J. Pneumococcal arthritis. J Rheumatol 1976; 3: 409-419.

23.Edwars G, Russell J. Pneumococcal arthritis complicating gout. J Rheumatol 1980; 7: 907-910.

24.Berrocal A, Silicani A, Calvo A. Artritis gonocócica. Diagnóstico. 1988; 22: 44-46. 
25.Brogadir S, Schimmer B, Myers A. Spectrum of gonococcal arthritis-dermatitis syndrome. Semin Arthr Rheum 1979; 8: 177-183. 